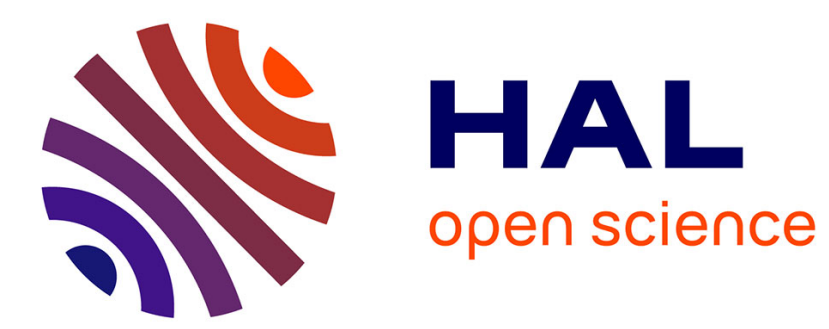

\title{
Le caroubier et la lutte contre l'incendie
}

Roger Marès

\section{To cite this version:}

Roger Marès. Le caroubier et la lutte contre l'incendie. 1971, pp.79-79. 10.4267/2042/20484 . hal03395052

\section{HAL Id: hal-03395052 \\ https://hal.science/hal-03395052}

Submitted on 22 Oct 2021

HAL is a multi-disciplinary open access archive for the deposit and dissemination of scientific research documents, whether they are published or not. The documents may come from teaching and research institutions in France or abroad, or from public or private research centers.
L'archive ouverte pluridisciplinaire HAL, est destinée au dépôt et à la diffusion de documents scientifiques de niveau recherche, publiés ou non, émanant des établissements d'enseignement et de recherche français ou étrangers, des laboratoires publics ou privés. 


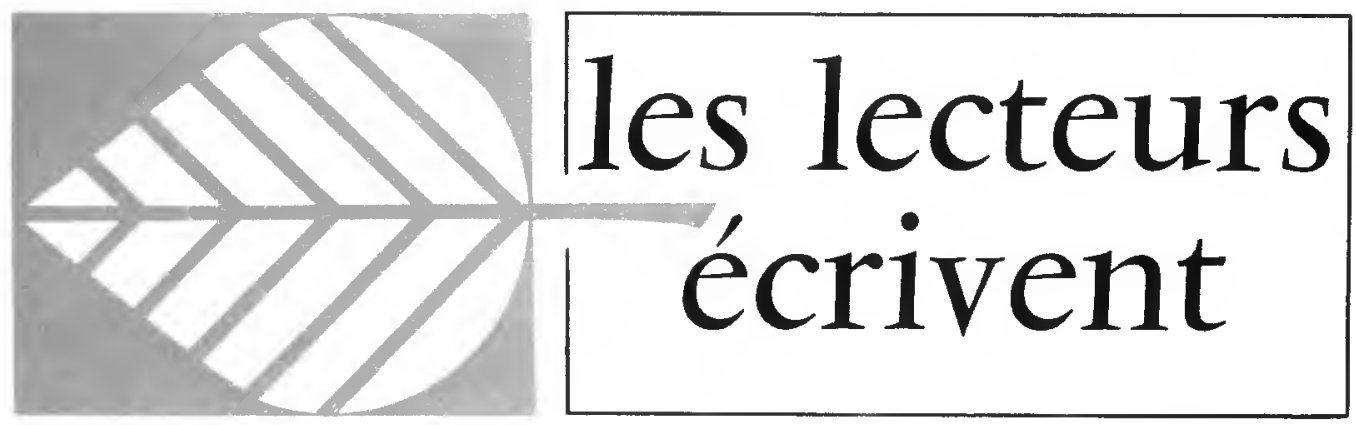

\section{LE CAROUBIER, ET LA LUTTE CONTRE L'INCENDIE}

Dans sa note "A propos des Eucalyptus ", Bouvarel dit qu'il s'agissait de trouver à l'origine, avec une forte production, un moyen de lutte contre les incendies en rompant la continuité du massif résineux. Le problème de lutte contre le feu par ce moyen ne se pose plus pour les Landes mais demeure pour le midi méditerranéen. Malheureusement, l'eucalyptus a bien de la peine à venir sur les mauvais sols secs et à éliminer les sous-bois ; le feu se propage dans ses peuplements à couvert trop clair, à moins d'interventions énergiques (et coûteuses) pour détruire le maquis.

Là où il n'est pas possible d'installer l'eucalyptus, je pense qu'il pourrait être remplacé par une autre essence qui arrête de façon remarquablement efficace le feu : le caroubier. J'al vu des incendies violents, avec bon vent, en forêt de pin d'Alep à sous étage de maquis dense, feu de cimes et feu de sous-bois, arrêtés par des caroubiers dont seule la moitié exposée au feu a été brûlée, l'autre moitié demeurant verte. Quant au sous-bois, il n'existe pas sous le couvert dense de cet arbre et le feu s'arrête faute d'aliment.

Le caroubier a certes des défauts : il reprend très difficilement, il pousse lentement, les inflorescences mâles sentent abominablement mauvais et il gèle. Le Service de la défense et restauration des Sols était arrivé à un très bon pourcentage de reprise ; notre métier est une longue patience et les forestiers doivent prévoir l'avenir ; lorsqu'en pépinière on greffe les sujets, on n'a plus que des sujets femelles, donc inodores.

II reste les gelées ; pourquoi ne pas s'appliquer comme on l'a fait pour d'autres essences à sélectionner des variétés résistant au froid?

Le caroubier a deux avantages : il produit des caroubes (fruit de peu de valeur, il est vrai), et il arrête le feu de lui-même. Il suffirait d'arroser avec des Canadairs derrière le rideau de caroubiers (plutôt que devant je crois, mais c'est à voir), afin d'empêcher les flammèches emportées par le vent de mettre le feu au-delà du pare-teu feuillu, pour que l'incendie soit le plus souvent arrêté.

II semble que la protection de la forêt méditerranéenne vaille la peine d'essayer.

R. MARES. 